2. Koster TD, Ramjankhan FZ, van de Graaf EA Luijk B, van Kessel DA, Meijer RC, et al. Crossed wiring closure technique for bilateral transverse thoracosternotomy is associated with less sternal dehiscence after bilateral sequential lung transplantation. J Thorac Cardiovasc Surg. 2013;146:901-5.

http://dx.doi.org/10.1016/ j.jtcvs.2013.11.008

\section{FATE OF THE \\ PRESERVED AORTIC ROOT IN ACUTE TYPE A AORTIC DISSECTION \\ To the Editor:}

I read with great interest the article by Rylski and colleagues ${ }^{1}$ regarding the fate of unreplaced aortic root in patients with conservative aortic root repair for acute type A aortic dissection. By retrieving data concerning 119 patients undergoing supracoronary ascending aortic replacement for acute type A aortic dissection, they found that dissection of all aortic sinuses of Valsalva at the index procedure was an independent predictor for aortic root reoperation (odds ratio, 3.57 ; $95 \%$ confidence interval, 1.36 9.35; $P<.01)$. During the follow-up period, 10 patients underwent reoperative surgery for aortic root replacement as a result of new-onset aortic root disease, including aortic root aneurysm, aortic valve insufficiency, and suture false aneurysm.

Note that reoperative surgery was performed in these 10 patients because of new-onset aortic root disease. Logically, factors determining new-onset root disease are also responsible for predicting reoperative surgery. How do Rylski and colleagues explain the absence of correlation between dissection of all aortic sinuses and new-onset aortic disease (odds ratio, 1.28; 95\% confidence interval, $0.49-3.37 ; P=.62$ ).

Rylski and colleagues ${ }^{1}$ identified the extension of the dissection to the iliac arteries as another risk factor for secondary aortic root disease. Reports from the literature are sparse, with only a very limited number of studies published on the topic. ${ }^{2,3}$ Ro and colleagues ${ }^{4}$ recently published a retrospective study including 196 patients with an aortic root conservative repair for acute type A aortic dissection. The cutoff level for replacing the aortic root at the time of initial surgery remains controversial; however, the results of the study of Ro and colleagues ${ }^{4}$ provide insights into the extent of aortic valve regurgitation and aortic root dilatation in this subset of patients, as well as a clearer indication for aortic root replacement during the initial procedure. They clearly demonstrate that patients with an aortic root diameter larger than 47 $\mathrm{mm}$ are at an increased risk for development of a root aneurysm, with subsequent intervention.

Taking into consideration these conclusions, it is easier to recognize those patients with acute type A aortic dissection in whom aortic root disease will develop during the follow-up. More aggressive approaches should therefore be considered for patients who have aortic root dissection of all sinuses, aortic root diameter larger than $47 \mathrm{~mm}$, or dissection involving iliac arteries.

Jamil Hajj-Chahine, MD Department of Cardiothoracic Surgery

University Hospital of Poitiers Poitiers, France

\section{References}

1. Rylski B, Beyersdorf F, Blanke P, Boos A, Hoffmann I, Dashkevich A, et al. Supracoronary ascending aortic replacement in patients with acute aortic dissection type A: what happens to the aortic root in the long run? J Thorac Cardiovasc Surg. 2013;146:285-90.

2. Concistrè G, Casali G, Santaniello E, Montalto A, Fiorani B, Dell'Aquila A, et al. Reoperation after surgical correction of acute type A aortic dissection: risk factor analysis. Ann Thorac Surg. 2012;93:450-5.

3. Dell'aquila AM, Concistrè G, Gallo A, Pansini S, Piccardo A, Passerone G, et al. Fate of the preserved aortic root after treatment of acute type A aortic dissection: 23-year follow-up. J Thorac Cardiovasc Surg. 2013;146:1456-60

4. Ro SK, Kim JB, Hwang SK, Jung SH, Choo SJ, Chung $\mathrm{CH}$, et al. Aortic root conservative repair of acute type A aortic dissection involving the aortic root: fate of the aortic root and aortic valve function. J Thorac Cardiovasc Surg. 2013;146:1113-8.

\section{http://dx.doi.org/10.1016/} j.jtcvs.2013.10.074

\section{Reply to the Editor:}

We value receiving useful feedback in another letter to the Editor from Dr Hajj-Chahine. ${ }^{1}$ We also appreciate his summary of our results ${ }^{2}$ and his question regarding the factors predicting new-onset aortic root disease and aortic root reoperation after surgery for acute type A aortic dissection with preservation of the sinus segment.

In our study of 119 patients with acute type A aortic dissection who underwent emergency ascending aortic replacement with sinus segment preservation, 26 patients exhibited evidence of new-onset aortic root disease during the follow-up period. Of these 26 patients, 10 required secondary proximal surgery. Dissection of all aortic sinuses of Valsalva was an independent predictor for aortic root reoperation (odds ratio [OR], 6.01; $P<.05$ ). However, this risk factor was not associated with new-onset aortic root disease (OR, 1.28; $P=.62)$. A similar discrepancy was observed regarding dissection extending to the pelvic arteries, which was predictive of new-onset aortic root disease (OR, 3.57; $P<.01)$ but was not predictive of root reoperation (OR, $1.65 ; P=.48)$. Although at first view, the predictors of new-onset aortic root disease might also predict aortic root repeat interventions, one should remember that this was an analysis of risk factors in 2 different groups, because not every case of aortic root disease requires repeat intervention. The risk factors for new-onset aortic root disorders and for root reoperations could, therefore, differ.

The advantages of aortic root preservation, such as avoiding coronary artery manipulation, reducing the crossclamp time, eliminating the risk of prosthetic valve endocarditis, and avoiding the permanent need for 
anticoagulation with mechanical valve replacement, should be balanced against the risk of proximal reoperation during follow-up. Regarding the published experiences of centers favoring aortic root preservation in the setting of acute type A dissection, it has been our institution's policy to consider more definitive aortic root repair for patients presenting with dissection of all sinuses, an aortic root diameter $>47 \mathrm{~mm}$, or dissection extending to the iliac arteries. ${ }^{2-4}$

Bartosz Rylski, MD

Friedhelm Beyersdorf, MD, PhD

Matthias Siepe, $M D$

Heart Center Freiburg University

Freiburg, Germany

\section{References}

1. Hajj-Chahine J. Fate of the preserved aortic root in acute type A aortic dissection. J Thorac Cardiovasc Surg. 2014;147:1112.

2. Rylski B, Beyersdorf F, Blanke P, Boos A, Hoffmann I, Dashkevich A, et al. Supracoronary ascending aortic replacement in patients with acute aortic dissection type A: what happens to the aortic root in the long run? J Thorac Cardiovasc Surg. 2013;146:285-90.

3. Concistrè G, Casali G, Santaniello E, Montalto A, Fiorani B, Dell'Aquila A, et al. Reoperation after surgical correction of acute type A aortic dissection: risk factor analysis. Ann Thorac Surg. 2012;93:450-5.

4. Ro SK, Kim JB, Hwang SK, Jung SH, Choo SJ, Chung $\mathrm{CH}$, et al. Aortic root conservative repair of acute type A aortic dissection involving the aortic root: fate of the aortic root and aortic valve function. J Thorac Cardiovasc Surg. 2013;146:1113-8.

http://dx.doi.org/10.1016/ j.jtcvs.2013.11.005

\section{FIBROSING INTERSTITIAL} PNEUMONIA: IS MECHANICAL VENTILATION ALWAYS THE FINAL ALTERNATIVE FOR THE INTENSIVIST?

\section{To the Editor:}

Currently, invasive mechanical ventilation (IMV) in patients with fibrosing interstitial pneumonia is a devastating situation in the intensive care unit (ICU). After 2 decades, the prognosis is still poor.

Gaudry and colleagues, ${ }^{1}$ in an original retrospective multicenter French study, describe short- and long-term outcomes in critically patients with fibrotic lung diseases undergoing IMV. In their view, more frequent use of lung protective strategies may influence poor outcomes, and individual evaluation case-by-case evaluation is needed for appropriate discrimination of ICU patients. Their arguments are solid, rational, and comprehensive for current practice and across all published studies, although major drawbacks of this study were its retrospective design and limited number of patients, Obviously, the recommendations are reasonable and appropriate; however, some points need to be taken into account:

First, the authors did not describe reasons for underuse of lower-level aggressive ventilation alternatives before IMV in these populations. Were the use of noninvasive ventilation and criteria for IMV in this study reflected properly? Recently, new and promising observations have emerged: (1) Although there is still only a small number of studies, early use of noninvasive ventilation in selected patients may avoid IMV and improve clinical conditions at ICU admission. $^{2}$ (2) Nasal high-flow cannulation may improve oxygenation in concert with low positive endexpiratory pressure in selected patients. Some patients with pulmonary fibrosis have been treated under expanded indications for nasal high-flow cannulation with promising results. ${ }^{3}$

Second, it is interesting that patients who met criteria for lung transplant and were breathing spontaneously with noninvasive ventilation have shown the best outcome as bridge to lung transplant and adequate results after bilateral lung transplant. ${ }^{4}$ These are promising alternatives to IMV for selected patients. ${ }^{2-4}$

Third, lung-protective ventilation arguably provides the best hope for good results of IMV in these patients. It is a reasonable hope; however, lung damage is currently equally associated with high levels of inspiratory oxygenation fraction and low tidal volume with high or normal positive end-expiratory pressure. ${ }^{5}$ Although large, prospective studies are nonexistent, it is a promising avenue.

Finally, it would be interesting to know details regarding survivors that are lacking in these studies, such as measurements of health-related quality of life, and the influence of specific natural history, such as rates of hospital admission and exacerbations after ICU discharge and impact of early pulmonary rehabilitative programs.

Further large international database studies will illuminate solid bases to define risk factors and prognosis in these directions.

Antonio M. Esquinas, MD, PhD,

FCCP

Intensive Care Unit and No Invasive Ventilatory Unit

Hospital Morales Meseguer

Murcia, Spain

\section{References}

1. Gaudry S, Vincent F, Rabbat A, Nunes H, Crestani B, Naccache JM, et al. Invasive mechanical ventilation in patients with fibrosing interstitial pneumonia. J Thorac Cardiovasc Surg. 2014;147:47-53.

2. Güngör G, Tatar D, Saltürk C, Cimen P, Karakurt Z, Kirakli C, et al. Why do patients with interstitia lung diseases fail in the ICU? A 2-center cohort study. Respir Care. 2013;58:525-31.

3. Bräunlich J, Beyer D, Mai D, Hammerschmidt S, Seyfarth HJ, Wirtz H. Effects of nasal high flow on ventilation in volunteers, COPD and idiopathic pulmonary fibrosis patients. Respiration. 2013;85: 319-25.

4. Crotti S, Iotti GA, Lissoni A, Belliato M, Zanierato M, Chierichetti $\mathrm{M}$, et al. Organ allocation waiting time during extracorporeal bridge to lung transplant affects outcomes. Chest. 2013;144:1018-25.

5. Altemeier W, Sinclair SE. Hyperoxia in the intensive care unit: why more is not always better Curr Opin Crit Care. 2007;13:73-8.

\section{http://dx.doi.org/10.1016/} j.jtcvs.2013.09.077

\section{Reply to the Editor:}

We thank Dr Esquinas for his comments and interest in our work. ${ }^{1}$ First, we would like to underline that our goal was not to promote invasive mechanical ventilation (IMV) for patients with end-stage fibrosing interstitial pneumonia but rather to provide an update on their prognosis. Obviously, 